\begin{tabular}{|c|l|}
\hline Title & Formation of porous anodic films on Ti-Si all loys in hot phosphate glycerol electrolyte \\
\hline Author(s) & Habazaki, H.; Oikawa, Y.; Fushimi, K.; Shimizu, K.; Nagata, S.; Skeldon, P.; Thompson, G. E. \\
\hline Citation & $\begin{array}{l}\text { Electrochimica A cta, 53(4), 1775-1781 } \\
\text { https://doi.org/10.1016/.electacta.2007.08.033 }\end{array}$ \\
\hline Issue Date & $2007-12$ \\
\hline Doc URL & http://hdl.handle.net/2115/33037 \\
\hline Type & article (author version) \\
\hline File Information & habasaki.pdf \\
\hline
\end{tabular}

Instructions for use 


\section{Formation of Porous Anodic Films on Ti-Si Alloys in Hot Phosphate-Glycerol Electrolyte}

H. Habazaki*, Y. Oikawa, K. Fushimi, K. Shimizu ${ }^{\#}$, S. Nagata ${ }^{\dagger}$, P. Skeldon ${ }^{\ddagger}$, G.E. Thompson ${ }^{\ddagger}$ Graduate School of Engineering, Hokkaido University, N13-W8, Sapporo 060-8628

\# University Chemical Laboratory, Keio University, 4-1-1 Hiyoshi, Yokohama 223-8521, Japan

${ }^{\dagger}$ Institute for Materials Research, Tohoku University, 2-1-1 Katahira, Sendai 980-8577, Japan

${ }^{\ddagger}$ Corrosion and Protection Centre, School of Materials, The University of Manchester, P.O.Box 88, Manchester M60 1QD, UK

* Corresponding author: Tel: +81-11-706-6575, e-mail: habazaki@eng.hokudai.ac.jp 
Abstract

Porous anodic films, with pore size of $\sim 10 \mathrm{~nm}$, have been developed by anodizing of magnetron sputtered Ti-25 at\% Si alloy at constant formation voltages in glycerol electrolyte containing dibasic potassium phosphate at $433 \mathrm{~K}$. The films, of amorphous structure, contain titanium and silicon species, as units of $\mathrm{TiO}_{2}$ and $\mathrm{SiO}_{2}$, throughout the film thicknesses, with negligible amounts of phosphorus species. The silicon is enriched in the film relative to the composition of the alloy, the level of enrichment suggesting that anion migration is increased in comparison with amorphous film growth at ambient temperature. In contrast to the behaviour of the alloy, essentially barrier films were formed on commercially pure titanium in the glycerol electrolyte, when a main anodic reaction was generation of oxygen, which was probably promoted by the development of anatase.

Keywords: self-organized porous oxide, anodic oxide films, Ti-Si alloy, glycerol electrolyte, crystallisation 


\section{Introduction}

Porous anodic films formed on titanium and other valve metals in fluoride-containing electrolytes are attracting much attention since their development in dilute HF electrolyte was first reported [1-3]. Such films, comprising arrays of self-organized nanotubes, have potential applications in photocatalysis, photoelectrolysis, and photovoltanics and as sensors [4]. In addition to the fluoride-containing aqueous electrolytes, it has been recently shown that porous anodic films can be formed in hot phosphate-glycerol electrolyte [5, 6], although initially the films were considered to be of barrier-type [7]. The formation of porous layers on aluminium, niobium and tantalum, with the presence of barrier layer separating the porous layer and metal substrate, has been confirmed by transmission electron microscopy (TEM). The film morphologies closely resemble that of the well-known porous anodic alumina produced in aqueous acid electrolytes [8], while the film compositions are virtually the oxides of the respective valve metals, with negligible incorporation of phosphorus species.

Although the mechanism of porous film formation in the phosphate-glycerol electrolyte is not yet known, the findings indicate that the electrolyte is useful for the preparation of porous anodic films on a range of valve metals. In the present work, the formation of amorphous, titania-based films, with fine porosity, is demonstrated for a Ti-Si alloy. The silicon addition to the titanium is important for sustaining the amorphous film structure. In its absence, the film transforms locally to anatase, which promotes oxygen evolution.

\section{Experimental}

The specimens used for anodizing were 99.5\% titanium sheet, polished mechanically with SiC to \#1500 grit, followed by mirror finishing with $3 \mu \mathrm{m}$ diamond, and Ti-25 at\% Si alloy, magnetron sputtered on to electropolished aluminium sheet or glass plate. The target 
used for sputtering was a 99.9\% titanium disk of $100 \mathrm{~mm}$ diameter and $6 \mathrm{~mm}$ thickness; four square silicon plates, with $15 \mathrm{~mm}$ sides, were placed symmetrically on the region of the target that is sputtered. In order to generate deposited films of uniform composition and thickness, the substrate holders were rotated around the central axis of the chamber as well as their own axis. The amorphous, single-phase nature of the deposits was confirmed by X-ray diffraction, as well as by selected area electron diffraction of an ultramicrotomed section.

The electrolyte used for anodizing was prepared by dissolving dibasic potassium phosphate in glycerol containing water of less than 0.5 mass\%. The concentration of the phosphate in the electrolyte was $0.8 \mathrm{~mol} \mathrm{dm}^{-3}$ at room temperature. Prior to anodizing, the electrolyte was held at a temperature of $453 \mathrm{~K}$ for $9 \mathrm{ks}$ to reduce the water content in the electrolyte [7]. The specimens, masked with silicone resin to define the surface area, were anodized at constant voltages of 10 to $50 \mathrm{~V}$ in the phosphate-glycerol electrolyte at $433 \mathrm{~K}$ using a two-electrode cell with a platinum counter electrode.

The surfaces of the anodized specimens were observed by field-emission gun scanning electron microscopy (FEGSEM), using a JEOL JSM6500 instrument operated at 15 kV. Cross-sections were observed by TEM, using a JEOL JEM 2000 FX instrument operated at $200 \mathrm{kV}$. Electron transparent sections, approximately $10 \mathrm{~nm}$ thick, were prepared by an RMC MT-7 ultramicrotome. Depth profiles of the anodized specimens were generated by glow discharge optical emission spectroscopy (GDOES), using a Jobin-Yvon 5000 instrument, in an argon atmosphere of $850 \mathrm{~Pa}$ with application of RF of $13.56 \mathrm{MHz}$ and power of $40 \mathrm{~W}$. Light emissions of characteristic wavelengths were monitored throughout the analysis with a sampling time of $0.01 \mathrm{~s}$ to obtain the depth profiles. The wavelengths of the spectral lines used were 365.350, 288.158, 178.287, 130.217 and $165.701 \mathrm{~nm}$ for titanium, silicon, phosphorus, oxygen and carbon, respectively. The signals were detected from a circular area of approximately $4 \mathrm{~mm}$ diameter. Compositions of specimens prior to and following 
anodizing were determined by Rutherford backscattering spectroscopy (RBS), using 2.0 MeV $\mathrm{He}^{2+}$ ions. The scattered particles were detected at $170^{\circ}$ to the incident beam direction, which was normal to the specimen surface. The data were analysed using the RUMP program. The structure of the anodic films was also examined using Jasco, NRS-2000 Raman spectrometer, under the irradiation of a green laser $(532 \mathrm{~nm})$ of $50 \mathrm{~mW}$.

Gas analysis was also performed during anodizing using a quadrupole mass spectrometer gas analyser (Balzers, Prisma QMS200M). For the gas analysis, anodizing was carried out under a flow of high purity argon gas.

\section{Results}

\subsection{Comparison of titanium and Ti-25 at\% Si alloy}

Figure 1 shows the markedly differing current-time transients of titanium and Ti-25 at\% Si alloy during anodizing at $10 \mathrm{~V}$ in the phosphate-glycerol electrolyte at $433 \mathrm{~K}$. For titanium, the current decreases gradually over the duration of anodizing of $1.8 \mathrm{ks}$. In contrast, the $\mathrm{Ti}-25$ at\% Si specimen reveals a rapid reduction of current, showing a minimum current density of $1.2 \mathrm{~A} \mathrm{~m}^{-2}$ after $150 \mathrm{~s}$, followed by a current increase to an approximately constant current density of $1.5 \mathrm{~A} \mathrm{~m}^{-2}$. The behaviour of the Ti-Si alloy resembles that of aluminium during formation of porous alumina films in aqueous acid electrolytes, such as sulphuric acid and oxalic acid. Analysis of evolved gas, using a mass spectrometer, during anodizing of titanium disclosed only hydrogen, originating at the cathode, and oxygen, originating at the anode (Fig. 2). However, for the Ti-Si alloy, only hydrogen gas was detected.

Scanning electron micrographs indicated the formation of a typical barrier film morphology on the titanium (Fig. 3(a)). The film thickness, according to GDOES, was less than $20 \mathrm{~nm}$, despite the relatively large current flowing during anodizing (Fig. 1). Thus, the film growth is not a main anodic reaction. In contrast, a porous anodic film developed on the 
Ti-Si alloy, with pores readily evident, of $\sim 10 \mathrm{~nm}$ size, at the film surface (Fig. 3(b)). The evolution of oxygen gas on the titanium is associated with the development of crystalline oxide in the anodic film. A Raman spectrum of the anodized titanium, with a low signal-to-noise ratio due to the thinness of the oxide developed, revealed clearly the peak at $140 \mathrm{~cm}^{-1}$, characteristic of anatase (Fig 4). In contrast, the spectrum of the anodized Ti-Si alloy indicated an amorphous oxide, as also confirmed by later electron diffraction.

Characterisation of the porous anodic films on the Ti-25 at\% Si alloy

Figure 5 shows transmission electron micrographs of ultramicrotomed sections of the Ti-25 at\% Si alloy anodized at $10 \mathrm{~V}$. Following anodizing for $100 \mathrm{~s}$, before the current minimum, a non-porous, barrier-type anodic film is formed (Fig. 5(a)). The thickness of the anodic film is $41 \pm 3 \mathrm{~nm}$, corresponding to a formation ratio of $4.1 \mathrm{~nm} \mathrm{~V} \mathrm{~V}^{-1}$. Associated with the high electrolyte temperature, the ratio is larger than that for a film formed in aqueous electrolyte at $293 \mathrm{~K}\left(1.5 \mathrm{~nm} \mathrm{~V}^{-1}\right)$ [9]. The increased formation ratio in the present electrolyte may be mainly due to temperature effect: the ionic resistivity generally decreases with increasing temperature. The film is apparently single-layered, contrasting with the films formed in aqueous conditions that comprise an outer silicon-free, $\mathrm{TiO}_{2}$ layer and an inner layer containing both silicon and titanium species [9]. After anodizing for 300 s (Fig. 5 (b)), development of the porous film is evident, with a barrier layer separating the substrate from the porous region. The thickness of the anodic film is $87 \pm 3 \mathrm{~nm}$, while that of the barrier layer is $30 \pm 3 \mathrm{~nm}$, which is slightly thinner than that formed at $100 \mathrm{~s}$ (Fig. 5 (a)). The selected area electron diffraction pattern of the anodic film reveals only a diffuse ring, showing that the anodic film is practically amorphous.

RBS spectra for the anodic films formed on the Ti-25 at\% Si alloy reveal the presence of titanium, silicon, and oxygen, the yield of the last species, at approximately 0.7 
$\mathrm{MeV}$, overlapping with the yield of aluminium substrate (Fig. 6). The simulated spectra, obtained using the thicknesses and compositions of the anodic films in Table 1, are fitted well with the respective experimental spectra. Thus, single-layered, oxide-based, anodic films are developed in this non-aqueous electrolyte, containing units of $\mathrm{TiO}_{2}$ and $\mathrm{SiO}_{2}$, with enrichment in silicon species compared with the alloy composition.

\section{Influence of formation voltage}

Current-time transients of the Ti-25 at\% Si alloy reveal that the current density at an anodizing time of $1.8 \mathrm{ks}$ is not greatly dependent upon the formation voltage, particularly in the range of 10 to $50 \mathrm{~V}$ (Fig. 7). However, the current density in the initial period of anodizing increases with the formation voltage. The current minimum appears more clearly at lower formation voltages and for anodizing at $50 \mathrm{~V}$, with no current minimum evident.

The surface morphologies of the porous anodic films formed after anodizing for 1.8 ks are dependent upon the formation voltages (Fig. 8). The pore size increases with the formation voltage, from $6 \pm 1 \mathrm{~nm}$ at $5 \mathrm{~V}$ to $20 \pm 2 \mathrm{~nm}$ at $50 \mathrm{~V}$, corresponding to 1.2 and 0.4 $\mathrm{nm} \mathrm{V}^{-1}$. Compared with the increased pore size with formation voltage, the number of pores in a unit surface area is not largely dependent upon the formation voltage. Further, nano-particles are present on the surface of the films formed at and above $10 \mathrm{~V}$, increasing markedly in abundance with the formation voltage.

The depth profiles of the anodic films formed at several formation voltages have been examined by GDOES. Examples for the 10 and $50 \mathrm{~V}$ films reveal the presence of titanium, silicon and oxygen species throughout the films, with silicon enriching at the surface region. The wavy profiles of titanium originate from an interference effect. Anodic films formed in aqueous electrolytes at ambient temperature are usually contaminated with species derived from electrolyte anions. However, the present films are practically free of phosphorus 
species, as in the cases of films formed on aluminium and tantalum in the same electrolyte [10]. Only the outermost film regions are contaminated with phosphorus species (Figs. 9 (b) and (d)), with a higher amount for the film formed at $50 \mathrm{~V}$. The carbon concentrations in both anodic films are apparently low.

\section{Discussion}

The findings disclose that porous film growth is predominant on the Ti-Si alloy in the present hot phosphate-glycerol electrolyte, while oxygen gas generation limits film growth on the $99.5 \%$ titanium. Such a difference in behaviour probably relates to structures of the oxides developed. From the Raman spectrum shown in Fig. 3, the formation of anatase is clear on the titanium. In contrast, the films formed on the Ti-Si alloy are practically amorphous, as indicated also by TEM (Fig. 5). The crystalline oxide provides an electron conducting path under the high electric field, enabling oxygen generation within the anodic oxide [11]. The crystallisation of amorphous anodic titania can occur on titanium at voltages of less than $10 \mathrm{~V}$ in aqueous electrolyte at ambient temperature [12]. The crystalline oxide is developed in the inner film material, which is formed at the metal/film interface by inward migration of oxygen species [13]. In the present anodizing conditions, the crystallisation and associated oxygen generation may occur more readily due to the elevated temperature. The crystallisation of amorphous titania is impeded by incorporation of silicon species, which are glass-formers. The silicon species stabilises the amorphous oxide, such that an amorphous oxide can form without gas generation on Ti-Si alloys in aqueous electrolytes at $298 \mathrm{~K}$ [14, 15]. The present results indicate that the oxide structure plays a crucial role in film formation in the phosphate-glycerol electrolyte.

The morphology of the porous films on the Ti-Si alloy in the present electrolyte resembles that of porous anodic alumina films formed in aqueous acid electrolytes [8], 
suggesting the possibility of a similar mechanism of the film formation. The growth of classical porous alumina proceeds under the condition that no film materials are developed at the film/electrolyte interface [16]. The condition arises when all $\mathrm{Al}^{3+}$ ions reaching the film surface are directly ejected into the electrolyte. During growth of anodic films on the Ti-Si alloys in aqueous electrolytes, silicon species are immobile, while titanium species migrate outward. Accordingly, for growth at high current efficiency, the films are two-layered, comprising an outer silicon-free layer, developed at the film/electrolyte interface, and an inner silicon-containing layer, developed at the alloy/film interface. However, as evident from results of TEM, RBS and GDOES, silicon species are distributed throughout the present films, including the barrier-type film formed initially. Assuming that silicon species are still immobile, the findings suggest that all the $\mathrm{Ti}^{4+}$ ions reaching the film/electrolyte interface may be ejected to the solution. The absence of film growth at this interface allows the development of embryo pores, which may then assist dissolution of the oxide. The immobility of silicon species in the growing film is likely since the field strength in the oxide is lower than that at ambient temperature, leading to the formation of a relatively thick barrier-type film at the low voltage of $10 \mathrm{~V}$ (Fig. 5).

As shown in Table 1, the anodic films are enriched in silicon species, similar to the inner layer of the films formed in aqueous electrolytes at ambient temperature $[9,14,15]$. In comparison with the composition of the inner anodic layer $\left(\left(\mathrm{Ti}_{0.55} \mathrm{Si}_{0.45}\right) \mathrm{O}_{2}\right)$ formed on the Ti-26 at\% Si alloy in ammonium pentaborate aqueous electrolyte [9], the enrichment of the silicon species is less significant. Under the assumption of the immobile nature of the silicon species and the ejection of mobile titanium species to the electrolyte, the composition of the present anodic film can be associated with the transport number of titanium ions, $\mathrm{t}^{+}$, during film growth, according to the following equation:

$$
t_{+}=\left(1-F_{S i, \text { alloy }} / F_{S i, \text { oxide }}\right) /\left(1-F_{S i, \text { oxide }}\right)
$$


in which $F_{\mathrm{Si} \text {, alloy }}$ is the atomic fraction of silicon in alloy and $F_{\mathrm{Si} \text {, oxide }}$ is the cationic fraction of silicon in anodic film. From the compositions of the anodic film (Table 1) and the alloy, $\mathrm{t}^{+}$is estimated to be 0.29 , which is lower than that films formed in ammonium pentaborate electrolyte at ambient temperature $\left(t_{+}=0.42\right)$. The reduced $t_{+}$is consistent with the fact that the $t_{+}$values for anodic tantala and niobia decrease with an increase in the electrolyte temperature $[17,18]$. The ejection of all of the outward migrating titanium ions to the electrolyte would reduce the efficiency of film growth to about $71 \%$, which is close to the efficiency indicated from the film composition according to RBS and the charge passed during anodizing. However, other work has suggested that films formed in phosphate-glycerol may allow electron conduction [19]. Dissolution of film species may also occur in the electrolyte, as indicated by the observation of nanoparticles, probably containing phosphorus, titanium and silicon species, at the surface of films formed at increased voltage. The particles may be developed either by precipitation of $\mathrm{Ti}^{4+}$ ions, which are dissolved at the pore base, or by selective dissolution of the outer regions of the film. Precipitation is possibly affected by the local water content of the electrolyte, which may be reduced in the pores due to the consumption of water to form the oxide. Further work is still required to understand clearly the factors affecting the efficiency of film growth and also to identify the mechanism of pore development, including the role of water in the electrolyte, which can terminate the porous film growth when present in sufficient amounts [7].

\section{Conclusions}

Porous anodic oxide films, with a morphology resembling classical porous anodic alumina formed in aqueous acid electrolytes, can be formed at constant voltage on titanium in hot 
phosphate-glycerol electrolyte by suppressing crystallization of anodic titania, which induces oxygen gas generation. The crystallization is impeded by incorporation of silicon species from the substrate. The silicon species are distributed throughout the film thickness, and are present in increased concentration with respect to the composition of the alloy, indicating the loss of titanium species to the electrolyte. The film composition is consistent with immobility of silicon species and outward migration of titanium species during film growth, with the transport number of the latter species being about 0.29 . Incorporation of phosphorus species from the electrolyte during anodizing is negligible. With increased formation voltage, nanoparticles are formed at the surface of the film.

\section{Acknowledgments}

The present work was supported in part by a Grant-in-Aid for Scientific Research, No. 16360353 from the Japan Society for the Promotion of Science. A part of this work was carried out under the Visiting Researcher's Programme of the Advanced Research Center of Metallic Glasses, Institute for Materials Research, Tohoku University.

\section{References}

[1] V. Zwilling, M. Aucouturier, E. Darque-Ceretti, Electrochim. Acta, 45 (1999) 921.

[2] D. Gong, C.A. Grimes, O.K. Varghese, W.C. Hu, R.S. Singh, Z. Chen, E.C. Dickey, J. Mater. Res., 16 (2001) 3331.

[3] R. Beranek, H. Hildebrand, P. Schmuki, Electrochem. Solid State Let., 6 (2003) B12.

[4] G.K. Mor, O.K. Varghese, M. Paulose, K. Shankar, C.A. Grimes, Sol. Energy Mater., 90 (2006) 2011.

[5] Q. Lu, G. Alcala, P. Skeldon, G.E. Thompson, M.J. Graham, D. Masheder, K. Shimizu, H. Habazaki, Electrochim. Acta, 48 (2002) 37. 
[6] Q. Lu, T. Hashimoto, P. Skeldon, G.E. Thompson, H. Habazaki, K. Shimizu, Electrochemical and Solid-State Letters, 8 (2005) B17.

[7] B. Melody, T. Kinard, P. Lessner, Electrochem. Solid State Let., 1 (1998) 126.

[8] J.P. O'Sullivan, G.C. Wood, Proc. R. Soc. London, A, 317 (1970) 511.

[9] M.T. Tanvir, K. Fushimi, K. Shimizu, S. Nagata, P. Skeldon, G.E. Thompson, H. Habazaki, Electrochim. Acta, (2007) in press.

[10] Q. Lu, P. Skeldon, G.E. Thompson, H. Habazaki, K. Shimizu, Thin Solid Films, 471 (2005) 118.

[11] C.K. Dyer, J.S.L. Leach, J. Electrochem. Soc., 125 (1978) 1032.

[12] A. Aladjem, J. Mater. Sci., 8 (1973) 688.

[13] H. Habazaki, M. Uozumi, H. Konno, K. Shimizu, P. Skeldon, G.E. Thompson, Corros. Sci., 45 (2003) 2063.

[14] H. Habazaki, K. Shimizu, S. Nagata, P. Skeldon, G.E. Thompson, G.C. Wood, J. Electrochem. Soc., 149 (2002) B70.

[15] H. Habazaki, K. Shimizu, S. Nagata, P. Skeldon, G.E. Thompson, G.C. Wood, Corros. Sci., 44 (2002) 1047.

[16] G.E. Thompson, Y. Xu, P. Skeldon, K. Shimizu, S.H. Han, G.C. Wood, Phil. Mag. B, 55 (1987) 651.

[17] Q. Lu, P. Skeldon, G.E. Thompson, D. Masheder, H. Habazaki, K. Shimizu, Corros. Sci., 46 (2004) 2817.

[18] S. Ono, M. Baba, M. Shimoyama, H. Asoh, in: V. Birss, L. Burke, A. R. Hillman, R. S. Lillard (eds.), Surface Oxide Film, The Electrochemical Society, p.133 (2004).

[19] Y.M. Li, L. Young, J. Electrochem. Soc., 148 (2001) B337. 
Figure captions

Fig.1 Current-time transients of titanium and magnetron sputtered Ti-25 at\% Si alloy during anodizing at $10 \mathrm{~V}$ in $0.8 \mathrm{~mol} \mathrm{dm}^{-3}$ dibasic potassium phosphate-containing glycerol electrolyte at $433 \mathrm{~K}$ for $1.8 \mathrm{ks}$.

Fig. 2 Ionic current transients for mass numbers (m/e) of 2, corresponding to hydrogen gas, and 32, corresponding to oxygen gas, measured during anodizing of titanium at $10 \mathrm{~V}$ in $0.8 \mathrm{~mol} \mathrm{dm}^{-3}$ dibasic potassium phosphate-containing glycerol electrolyte at $433 \mathrm{~K}$ under a flow of argon gas.

Fig. 3 Scanning electron micrographs of surfaces of anodic films formed on (a) titanium and (b) Ti-25 at\% Si alloy at $10 \mathrm{~V}$ in $0.8 \mathrm{~mol} \mathrm{dm}^{-3}$ dibasic potassium phosphate-containing glycerol electrolyte at $433 \mathrm{~K}$ for $1.8 \mathrm{ks}$.

Fig. 4 Raman spectrum of titanium anodized at $10 \mathrm{~V}$ in $0.8 \mathrm{~mol} \mathrm{dm}^{-3}$ dibasic potassium phosphate-containing glycerol electrolyte at $433 \mathrm{~K}$ for $1.8 \mathrm{ks}$. The Raman spectrum of anatase powder is also shown for comparison.

Fig. 5 Transmission electron micrographs of ultramicrotomed sections of Ti-25 at\% Si alloy anodized at $10 \mathrm{~V}$ in $0.8 \mathrm{~mol} \mathrm{dm}{ }^{-3}$ dibasic potassium phosphate-containing glycerol electrolyte at $433 \mathrm{~K}$ for (a) $100 \mathrm{~s}$ and (b) $300 \mathrm{~s}$.

Fig. 6 Experimental and simulated spectra of Ti-25 at\% Si alloy anodized at $10 \mathrm{~V}$ in $0.8 \mathrm{~mol}$ $\mathrm{dm}^{-3}$ dibasic potassium phosphate-containing glycerol electrolyte at $433 \mathrm{~K}$ for (a) $100 \mathrm{~s}$ and (b) $1.8 \mathrm{ks}$.

Fig. 7 Current-time transients of Ti-25 at\% Si alloy during anodizing at several voltages in 0.8 mol dm${ }^{-3}$ dibasic potassium phosphate-containing glycerol electrolyte at $433 \mathrm{~K}$ for $1.8 \mathrm{ks}$.

Fig. 8 Scanning electron micrographs of surfaces of the anodic films formed on $\mathrm{Ti}-25 \mathrm{at} \% \mathrm{Si}$ alloy at (a) $5 \mathrm{~V}$, (b) $10 \mathrm{~V}$, (c) $20 \mathrm{~V}$ and (d) $50 \mathrm{~V}$ in $0.8 \mathrm{~mol} \mathrm{dm}^{-3}$ dibasic potassium phosphate-containing glycerol electrolyte at $433 \mathrm{~K}$ for $1.8 \mathrm{ks}$. 
Fig. 9 GDOES depth profiles of the anodic films formed on Ti-25 at\% Si at (a) $10 \mathrm{~V}$ and (b) $50 \mathrm{~V}$ in $0.8 \mathrm{~mol} \mathrm{dm}^{-3}$ dibasic potassium phosphate-containing glycerol electrolyte at 433 $\mathrm{K}$ for $1.8 \mathrm{ks}$. 

(a)

Hescosy

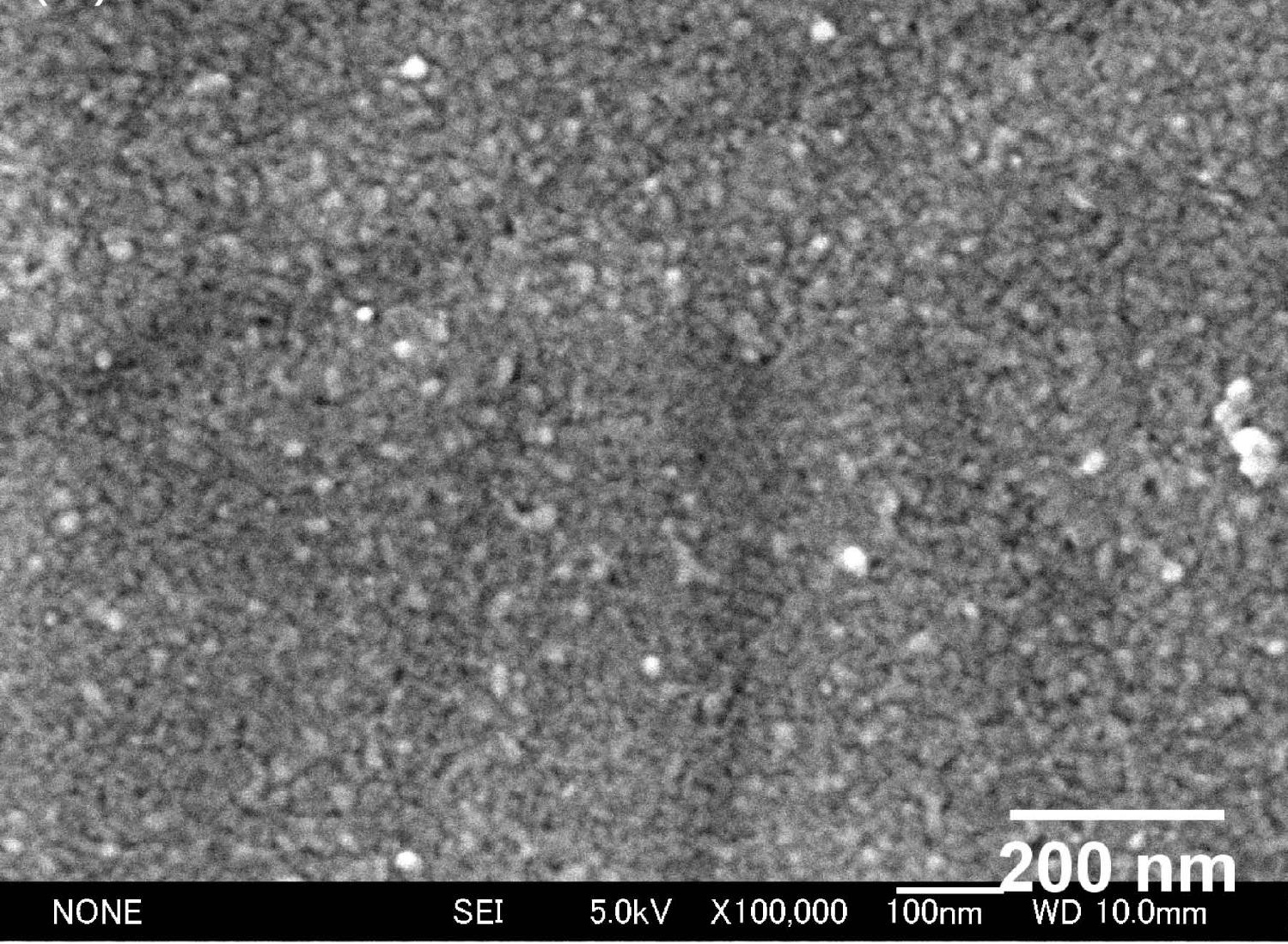

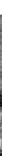

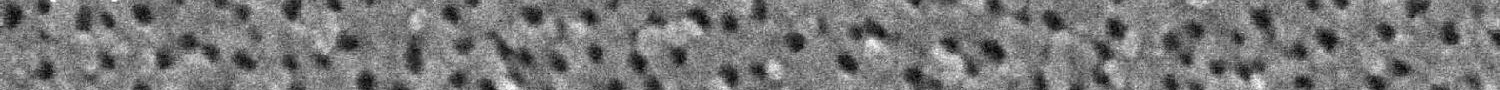

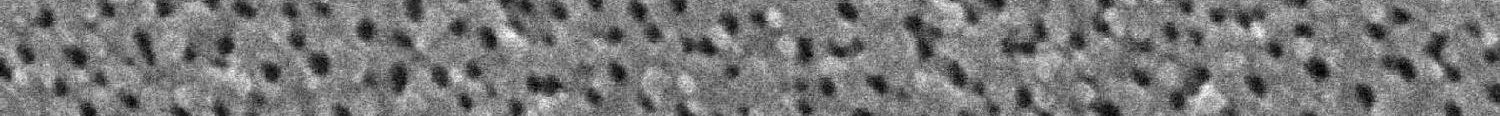

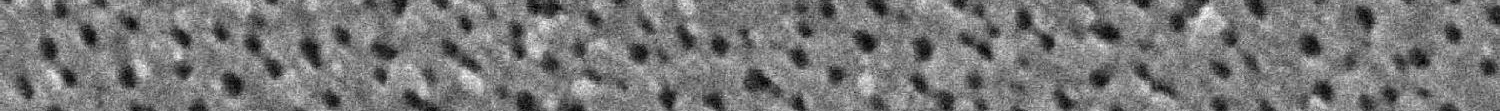

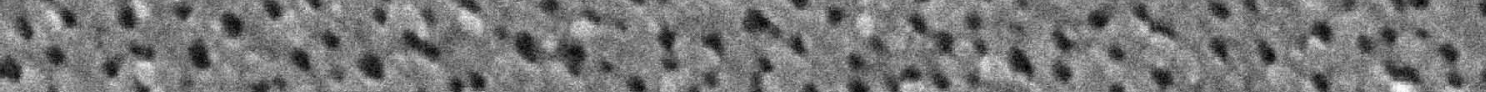

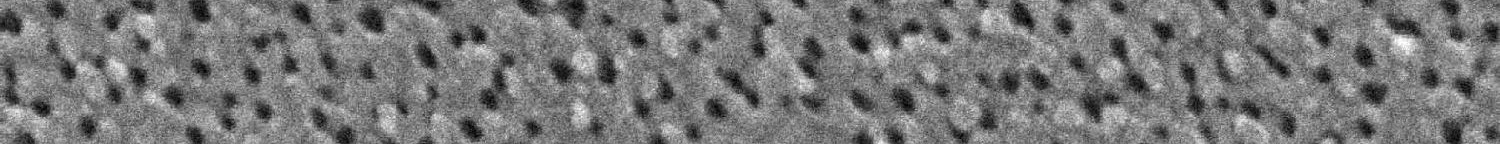

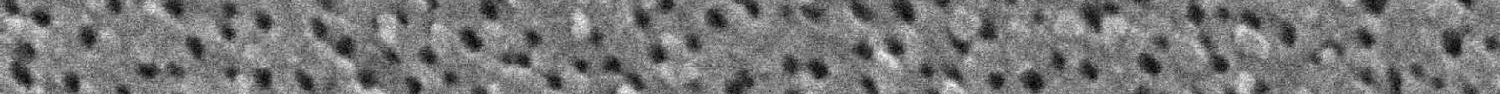

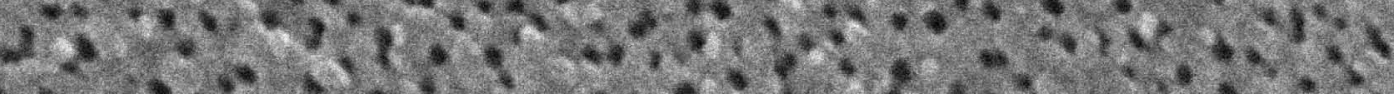

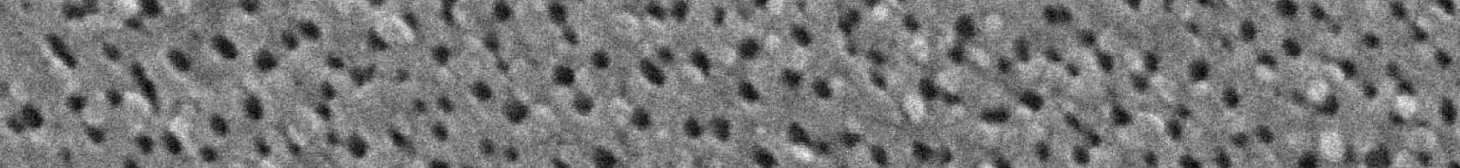

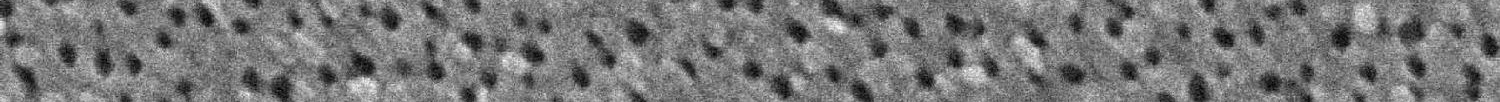

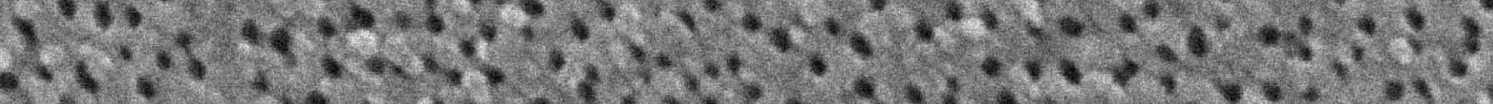
t.

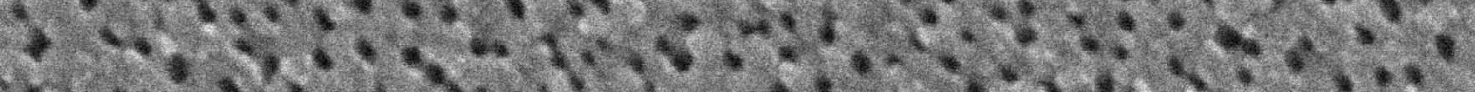

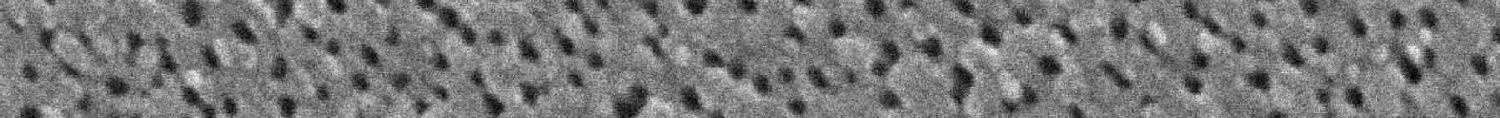

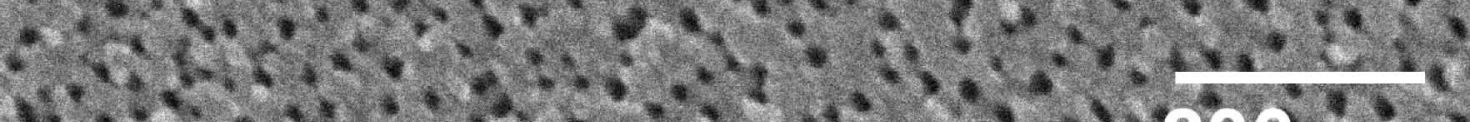

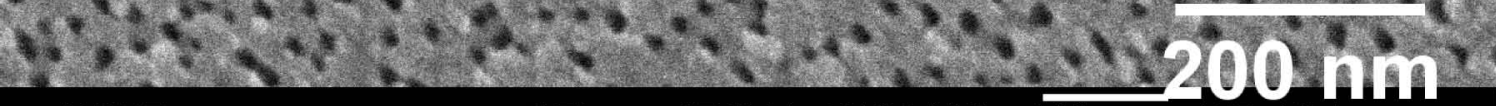
NONE SEI $\quad 15.0 \mathrm{kV} \times 100,000 \quad 100 \mathrm{~nm} \quad$ WD $10.1 \mathrm{~mm}$ 


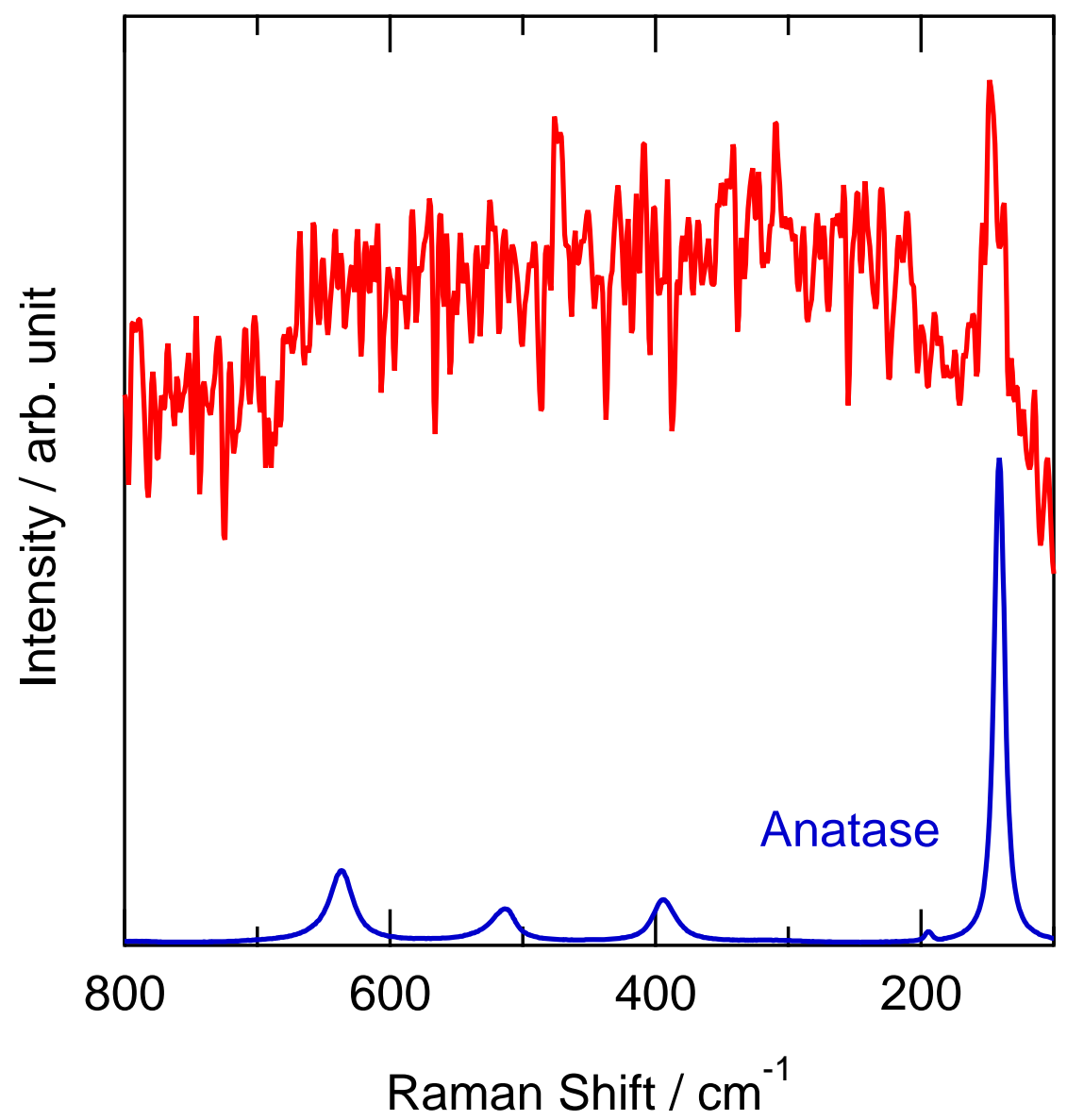




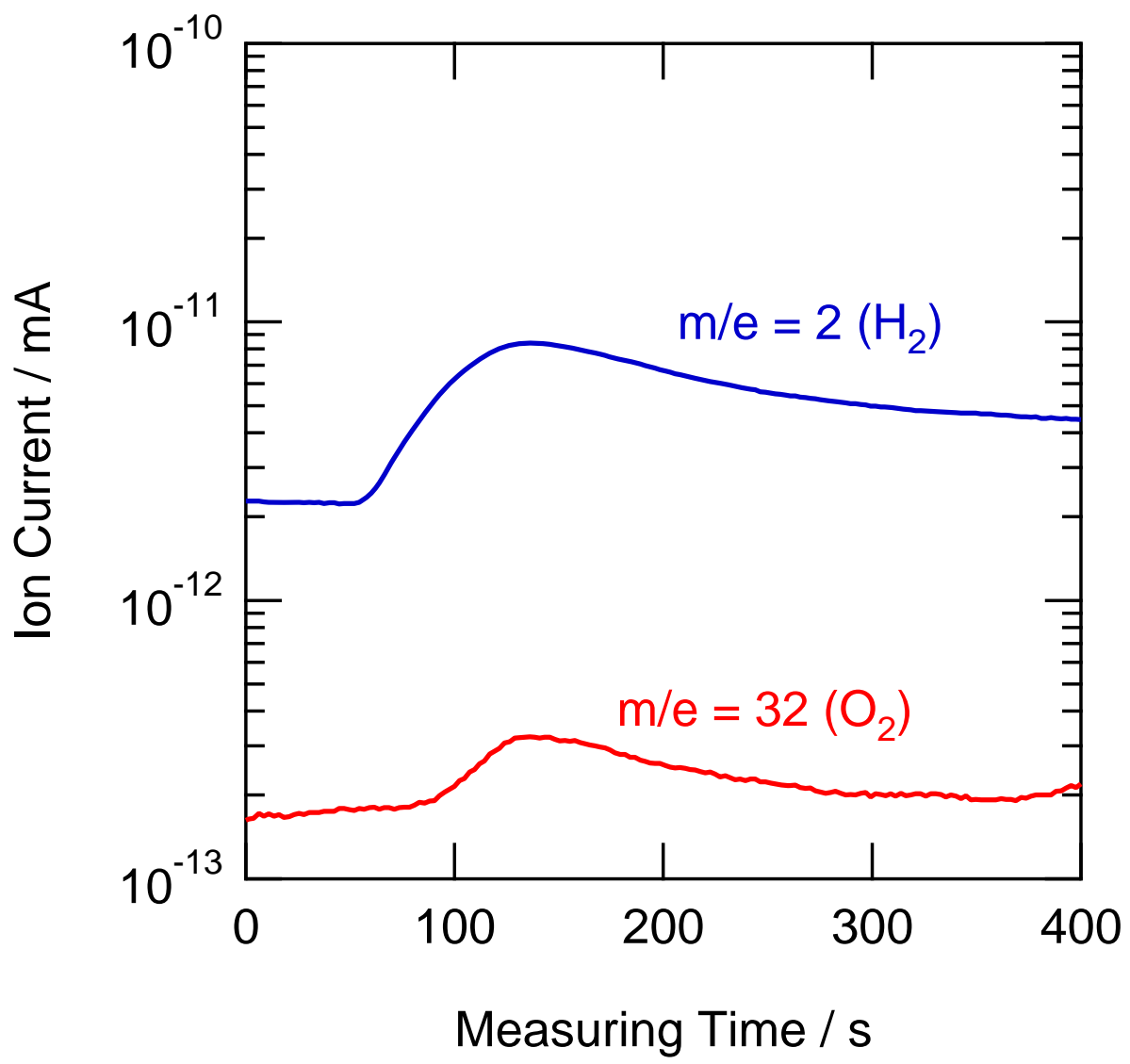


Anodic oxide

\section{Ti-Si alloy}

(b)

Ti-Si alloy

\section{Anodic oxide

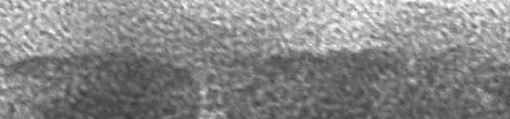


Energy / MeV

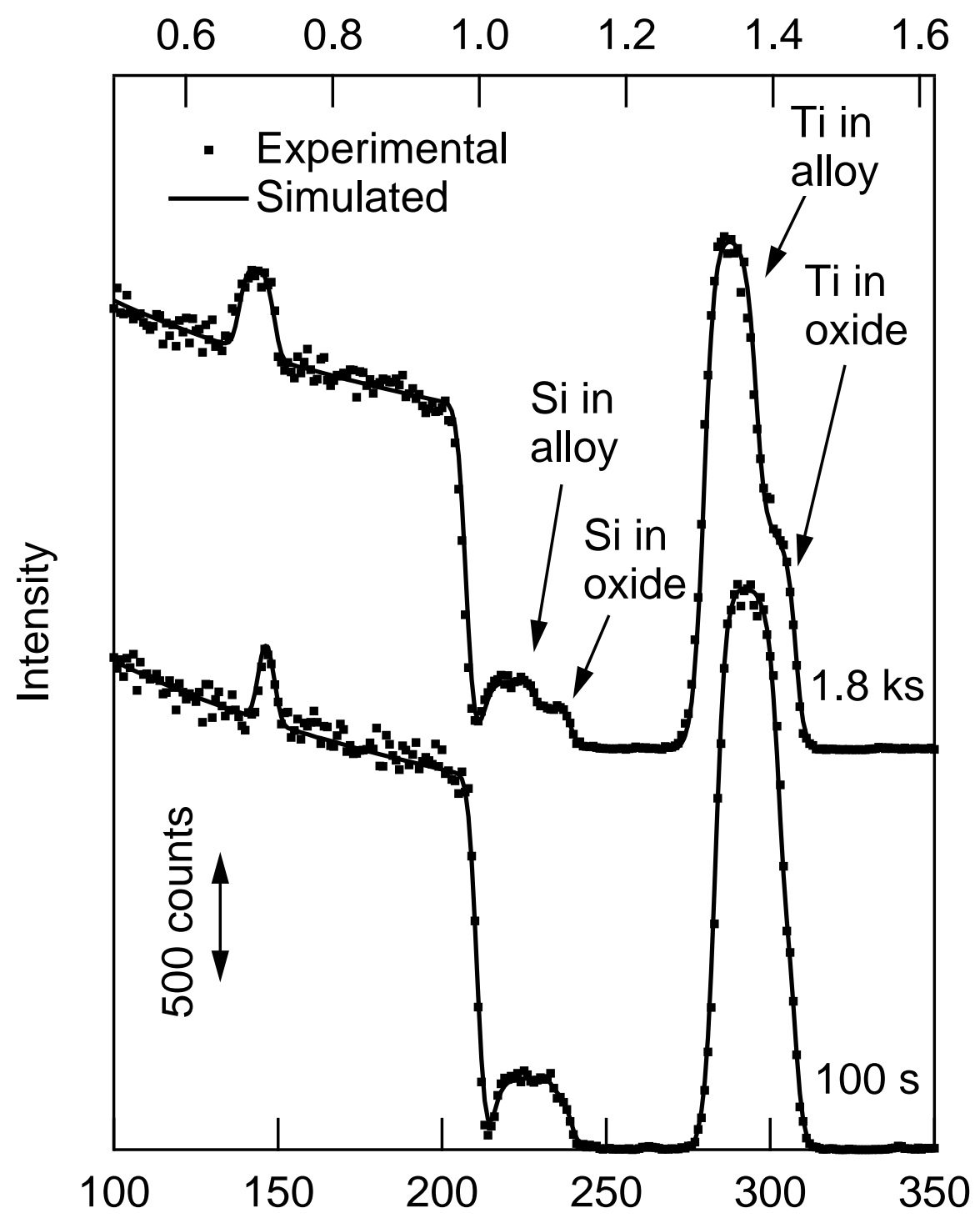

Channel Number 


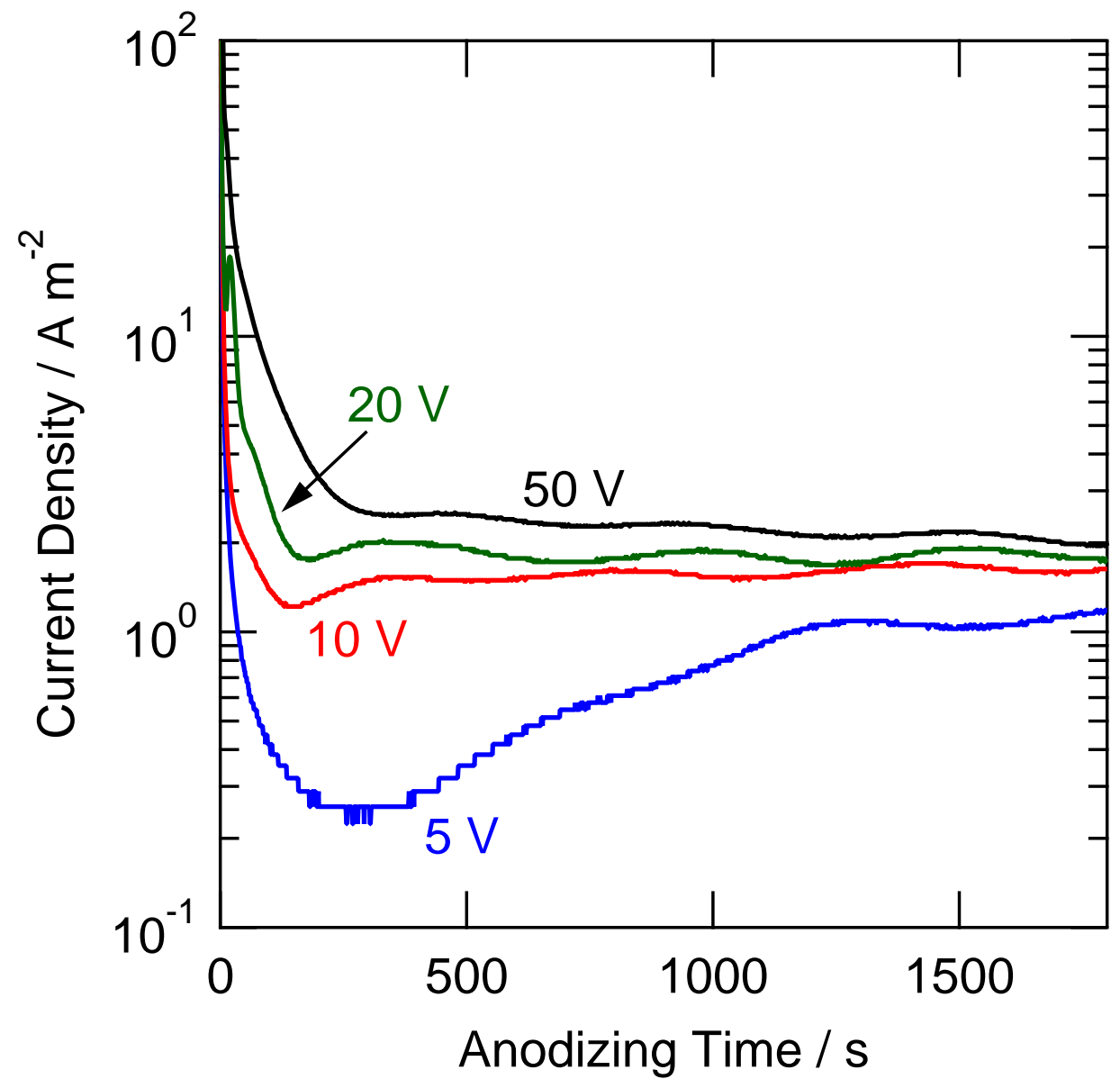




\section{(a)}

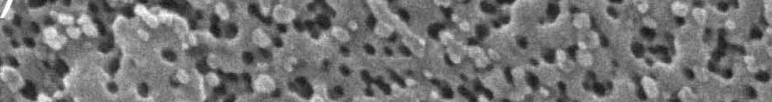

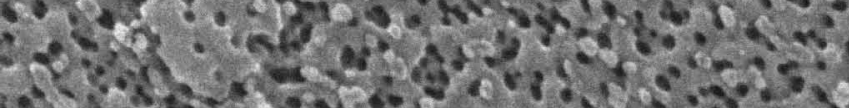

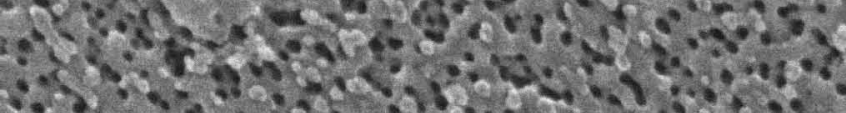

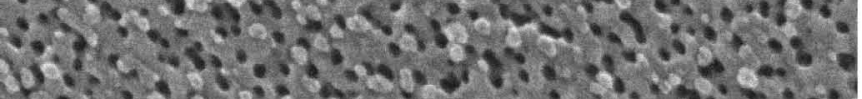

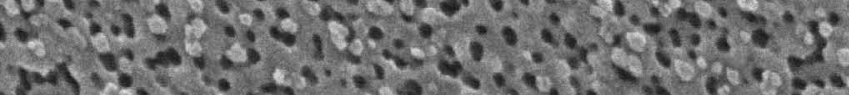

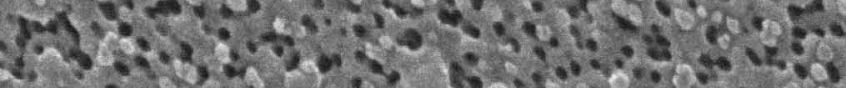

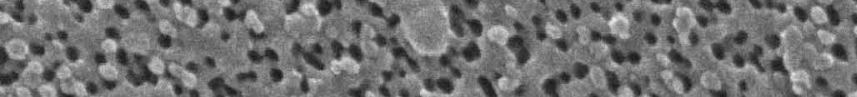

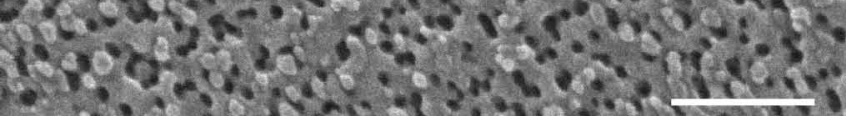

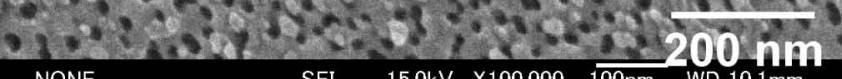

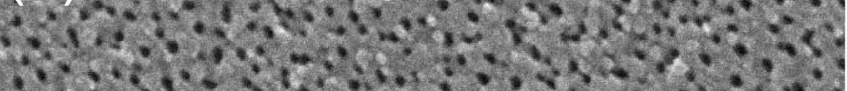

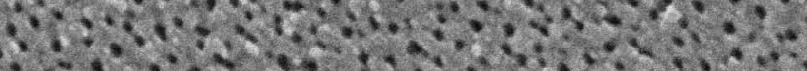

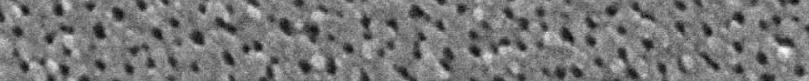

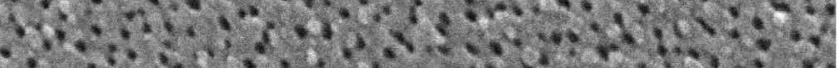

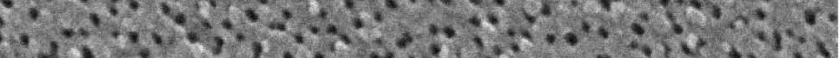

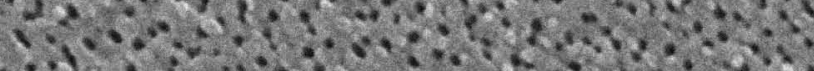

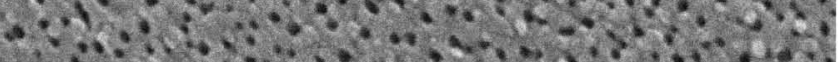

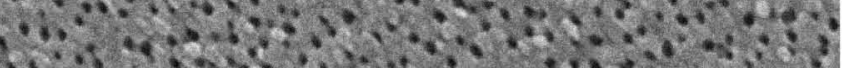

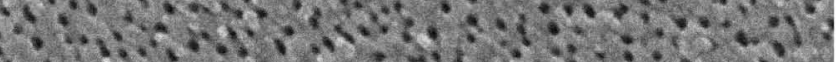

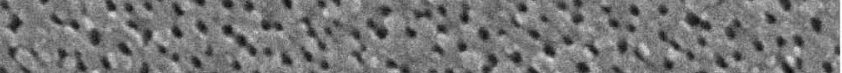

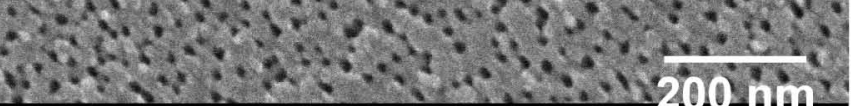
$\begin{array}{llllll}\text { NONE } & \text { SEI } & 15.0 \mathrm{kV} & \times 100,000 & 100 \mathrm{~nm} & \text { WD } 10.1 \mathrm{~mm}\end{array}$

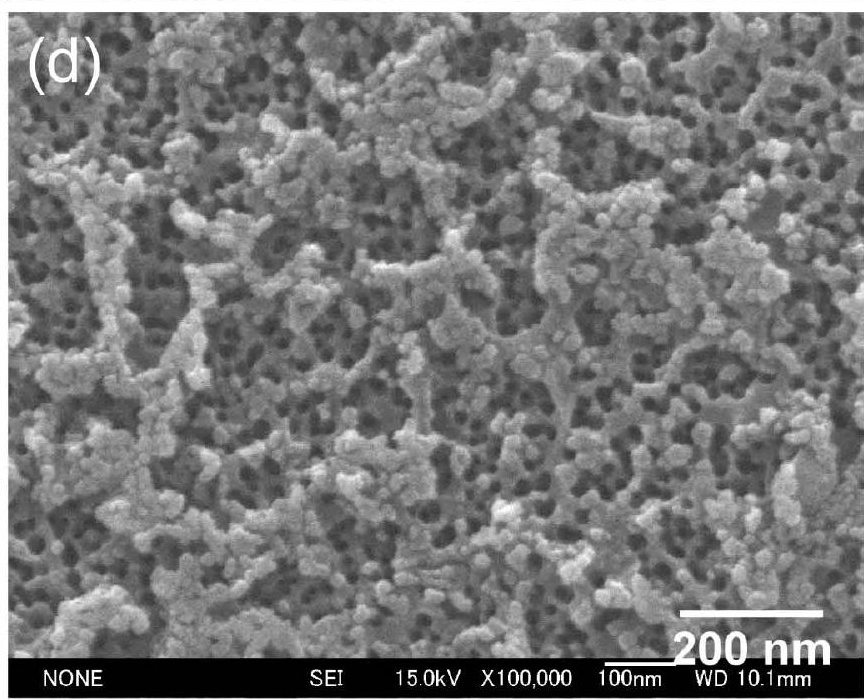


(a) 